\title{
Experimental Analysis of Solar Dryer for Agricultural and Food Products
}

\author{
Kshitij Moholkar, Akshay Jadhao, Rohit Chavan, Ravindra Bhosale, Kuldip Pukale
}

\begin{abstract}
The drying of various agricultural food products is from very far old centuries are under a presence of the sun, in this drying process has several demerits also i.e. spoiling to the skin due to a very high hot summer temperature, polluted air, dust and harmful effects of UV radiations. Hence only in the best weather, climatic conditions this process is suitable to the manpower, laborfarmers etc.Due to the cultural and industrial revolutions, the different artificial drying processes havecome into the practice but some of them has ultimate cost and some other parameters. Therefore, by using many more recent ideas and techniques of science we have developed most efficient and successful process of sun drying i.e. "solar dryer." this solar dryer totally utilizes the solar energy to heat up air and dry the agricultural products by gradual removing of moisture content from final product.

This paper represents the design, construction and experimentation of a portable solar dryer for various agricultural food preservations. In this solar dryer the heated air from a solar panel is passed through a food net or bed, and also at this time, the drying cabinet or interior absorbs the extra solar energy indirect type from the reflection mirror which we have adjusted newly to it.
\end{abstract}

Index Terms - solar energy, indirect type solar dryer, recent ideas.

\section{INTRODUCTION}

Now a days, renewable energy sources are playing very significant role. The main renewable sources are wind energy, solar energy, tidal energy, etc. The significant amount of energy is also generated through horizontal and vertical axis wind turbines [1-3].

The solar energy is employed in various applications. Solar dryers are devices that use solar energy of sun to dry substances, especially the substances which are used in our daily life. The heat from the sun coupled with the wind used to dry product so that it can be preserve for long time. There are different types of solar dryer including natural convection solar dryer and forced convection solar dryer. in natural convection airflow is created by buoyancy induce airflow but in case of forced convection air is created by using fans.In forced convection dryer base on mixed mode with direct and indirect heating. it gives better result as compare to open air dryer. Also drying is fast as compare to open air dryer. We also referred these authors.Recent developments in solar dryer are given below:

Some researchers reported the fruit dryers' study and characteristics of fruit dryers are presented along with various designs and constructions. Also, the problems associated with open-air sun drying are solved through the use of a solar dryer which comprises of a drying chamber and sometimes a collector. The natural convection solar dryer was developed; the drying and thermal analysis were done and tested to obtain some performance evaluation parameters. An experimental study was done for investigation of performance of a solar drying system and a system with an auxiliary heater as a supplement to the solar heat [4-13].

\section{EXPERIMENTAL CALCULATIONS}

1. Open Sun Drying

Initial Weight $=200 \mathrm{gm}$

Final Weight $=110 \mathrm{gm}$

Moisture Percent $=$

(InitialWeight - Final Weight)*100 / Initial Weight

$=(200-110) 100 / 200$

$=45 \%$

2. Solar Dryer

Initial Weight $=200 \mathrm{gm}$

Final Weight $=99 \mathrm{gm}$

Moisture Percent $=$

(Initial Weight - Final Weight)*100 / Initial Weight

$=(200-99) 100 / 200$

$=50.50 \%$

1. Open Sun Drying

Moisture Percent = $=45 \%$

2. Solar Dryer

Moisture Percent =

$50.50 \%$

Results:-

As per test conducted on

Ocimumtenuiflorum (Tulasi) for one hour

Kshitij Moholkar, Dept. of Mechanical Engg. SVERI'S COE, Pandharpur,India

Akshay Jadhao , Dept. Mechanical Engg. SVERI'S COE, Pandharpur, India

Rohit Chavan, Dept. Mechanical Engg. SVERI'S COE, Pandharpur, India Ravindra Bhosale, Dept. Mechanical Engg. SVERI'S COE,Pandharpur,India

Kuldip Pukale, Assistant Prof. , Dept. Mechanical Engg. SVERI'S COE, Pandharpur, India 
Table no. 1

\begin{tabular}{|l|l|l|l|l|}
\hline $\begin{array}{l}\text { Ti } \\
\text { me in } \\
\text { min }\end{array}$ & $\begin{array}{l}\text { Weight } \\
\text { red }^{\mathrm{n}} \text { after } \\
\text { open sun } \\
\text { drying in } \\
\text { gms }\end{array}$ & $\begin{array}{c}\text { Weight } \\
\text { red }^{\mathrm{n}} \text { after } \\
\text { drying } \\
\text { in solar } \\
\text { dryer gms }\end{array}$ & $\begin{array}{l}\text { Moistur } \\
\text { encentage } \\
\text { remove } \\
\text { d in open } \\
\text { sun drying }\end{array}$ & $\begin{array}{c}\text { Moistur } \\
\text { Percentage } \\
\text { remove } \\
\text { in solar } \\
\text { dryer }\end{array}$ \\
\hline 20 & 31.5 & 34.5 & 15.75 & 17.25 \\
\hline 40 & 30.5 & 33.5 & 31 & 34 \\
\hline 60 & 28 & 33 & 45 & 50.50 \\
\hline
\end{tabular}

\section{METHODOLOGY}

We constructed a portable solar dryer of indirect type working on forced convection. The CAD model of the dryer is shown in Fig. 1 and the actual developed dryer is presented in Fig. 2. Compared our dryer with open sun drying to check performance of our dryer.Dryer works with maximum efficiency as compared to open sun drying. We plotted graphs by making some calculations.

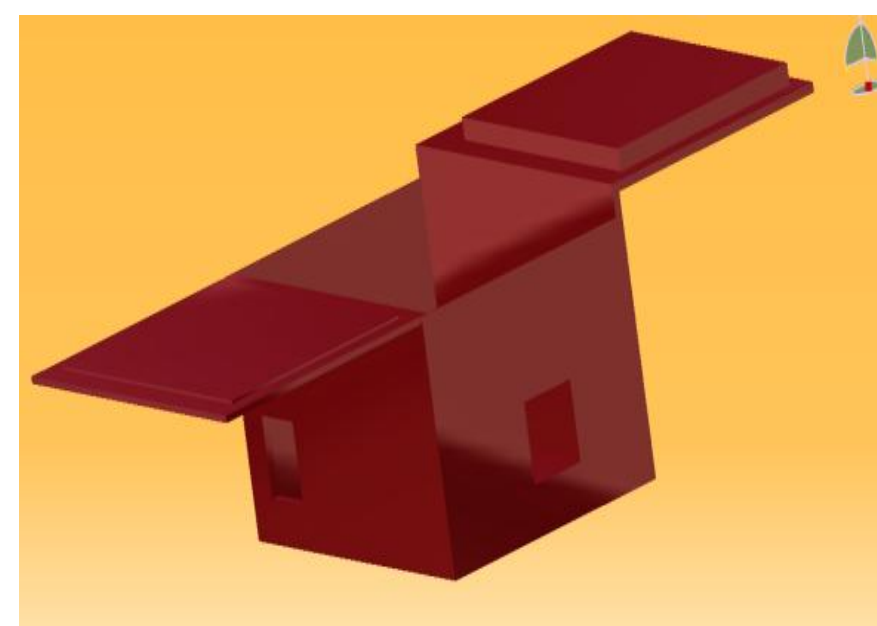

Fig. 1 Design of Model

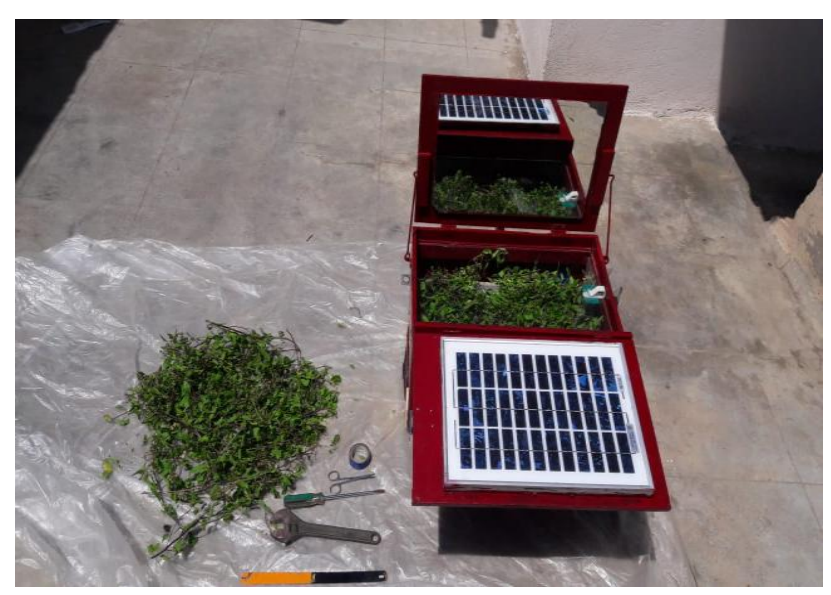

Fig.2 Actual Model Setup

\section{Abbreviations}

'gm' is used for grams.

'\%' used for percentage.

'DC' used for Direct Current.

'V' means Voltage.

'A' means Ampere.

\section{Machine Components Design:}

1. Battery(DC 12v)-It is used for storing energy from solar panel.

2. Switch- The switch is used for the on/off purpose of fans.

Solar Panel-It is used to absorb sunlight to generate energy

3. Fans(DC 12v 1.8A) -Fans are using to create airflow which deals with forced convection.

4. Inside Glass -It is used for enclose the system so that there is no leakage of air.

5. Mirror-It is used for the reflection of sunlight as per the changing direction of sun.

6. Aluminium Net Tray-To keep the desired product inside the used system

7. Briefcase-For making model portables

\section{Working of Model:}

In this solar dryer firstly some sun-rays follows on the solar panel, this solar panel absorbs to it, then through wiring system it transfers to the battery which stores the extracted energy from the solar panel. By using forced convection our solar dryer of indirect type operates $12 \mathrm{v}$ DC fans and dry products which are kept inside.

\section{RESULTS}

The weight reduction achieved by solar drying in comparison with solar drying is depicted in Fig. 3. The water content removal and moisture removal for sun drying and solar drying is presented in Figs. 4 and 5, respectively. It can be noted from these figures that the performance of solar dryer is noteworthy as compared to open sun drying.

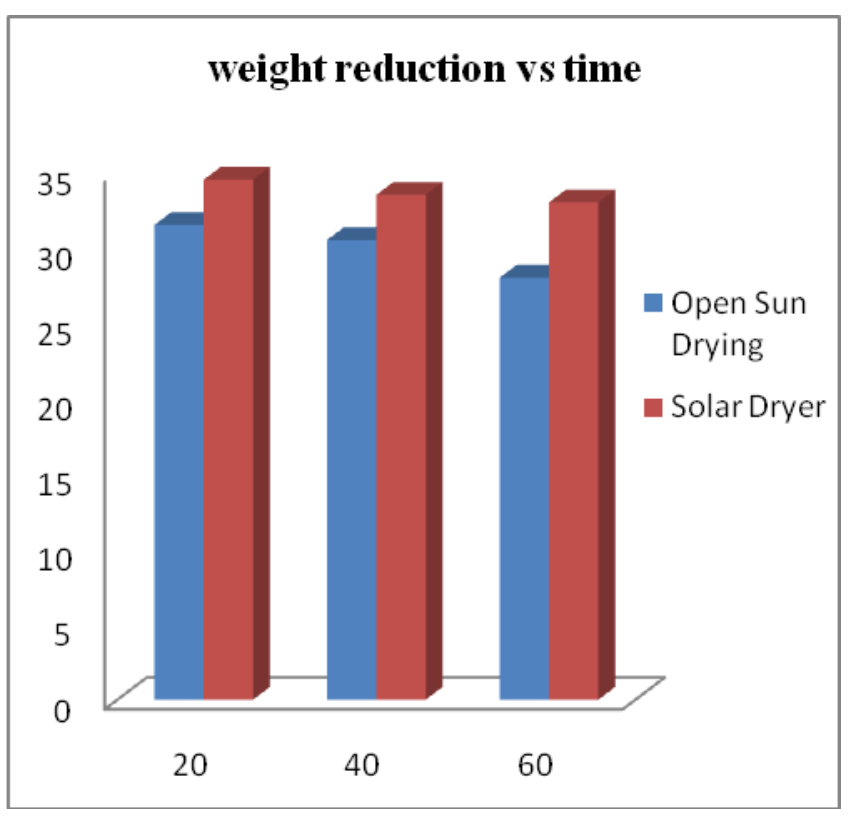

Fig. 3 Comparison of open sun and solar dryer after every 20 minutes

$\mathrm{X}$ Axis:-Time in minutes

Y Axis:-Weight reduction after drying in grams 


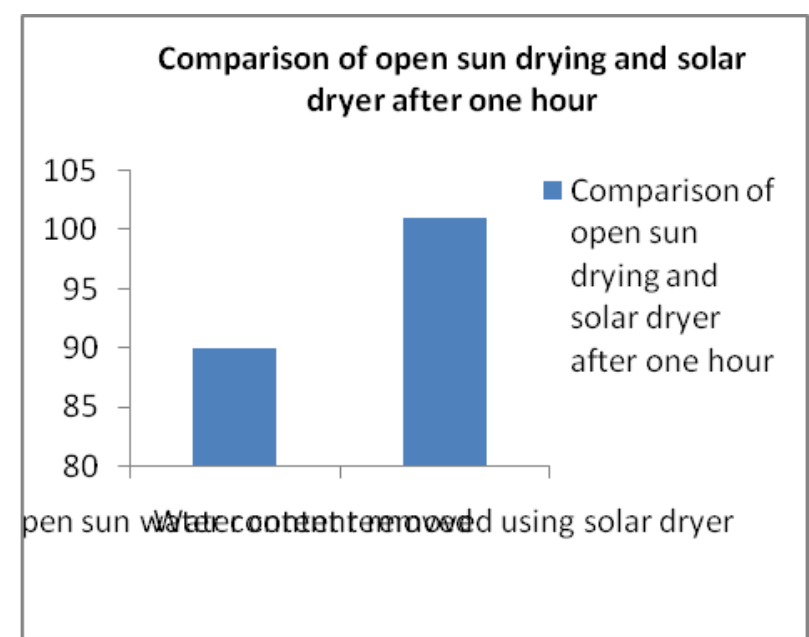

Fig.4 Comparison for water content removal

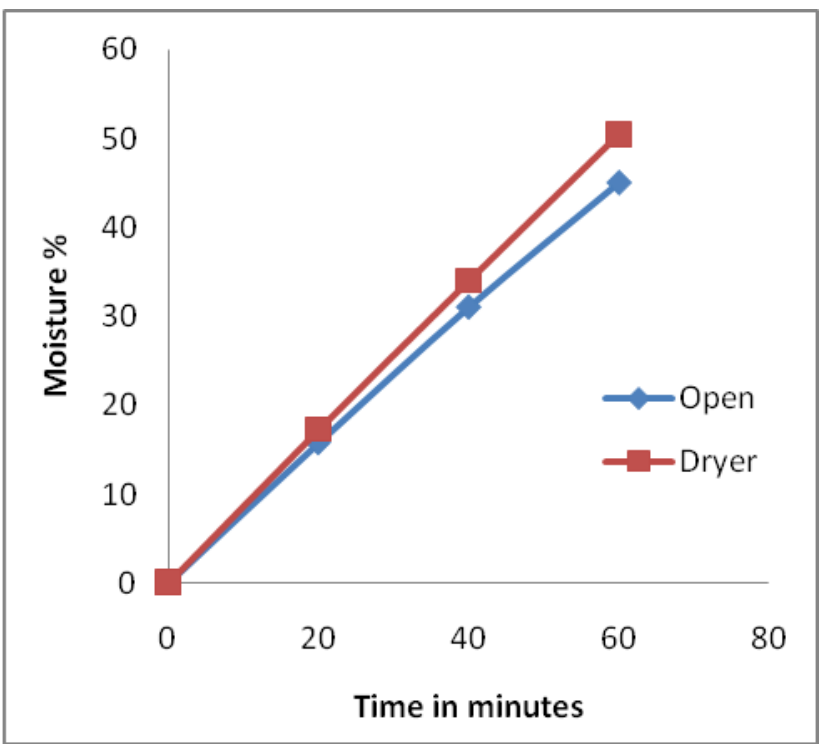

Fig.5 Moisture percent removal vs time

\section{CONCLUSION}

From above experimental analysis we have concluded that the solar dryer increases the temperature of ambient air upto maximum efficiency and dries the agricultural products, less care required for protection from rain, wind whirl, polluted air etc. as compared to the open sun drying. Hence this solar dryer is more effective and economical and acceptable.

\section{ACKNOWLEDGMENT}

The authors wish to thank Dr. B. P. Ronge the principal of College of Engineering, Pandharpur, Guide Prof. K.S. Pukale and RHRDF G.S. Kulkarni sir for completion of our project work.

\section{REFERENCES}

[1]. S.S. and Misal, N.D., 2012, December. Effect of some design parameters on performance of a shutter type vertical axis wind turbine. In ASME 2012 Gas Turbine India Conference (pp. 159-164). American Society of Mechanical Engineers.

[2]. Wangikar, S.S., Jagtap, S.U., Tarmude, A.B., Pore, A.S. and Shinde, S.P., 2013, December. Performance Analysis of Casement Type Vertical Axis Wind Turbine. In ASME 2013 Gas Turbine India Conference (pp. V001T07A004-V001T07A004). American Society of Mechanical Engineers.
[3]. Muttagi, V.R., Wangikar, S.S., Bhosale, S.S. and Bhosale, S.B., 2016, December. Optimization of Process Parameters for Shutter Type Vertical Axis Wind Turbine. In Techno-Societal 2016, International Conference on Advanced Technologies for Societal Applications (pp. 147-152). Springer, Cham.

[4]. Anil Kumar, RenuSingh,Om Prakash and AshutoshReview on global solar drying statusDecember, 2014 Agric Eng Int: CIGR Journal Vol. 16, No.4 161

[5]. R. Vidya Sagar Raju, R. Meenakshi Reddy and E. Siva ReddyDesign and Fabrication of Efficient Solar DryerR. Vidya Sagar Raju et al Int Journal of Engineering Research and Applications www.ijera.com ISSN: 2248-9622, Vol. 3, Issue 6, Nov-Dec 2013, pp.1445-1458

[6]. O. Adelaja and B. I. Babatope journal of Energy Volume 2013, Article ID 479894, 8 pages.

[7]. Abdul Jabbar N. Khalifa, Amer M. Al-Dabagh, and W. M Al-Mehemdi

[8]. ISRN Renewable EnergyVolume 2012, Article ID 789324, 8 pages

[9]. K. Bala, M. R. A. Mondol, B. K. Biswas, B. L. Das Chowdury, S. Janjai, "Solar drying of pineapple using solar tunnel Drier", Renewable Energy, 2003, Vol. - 28, pp. 183-190.

[10]. George, R. McGruder and K. Torgerson, "Determination of Optimal Surface Area to Volume Ratio for Thin-Layer Drying of Breadfruit", International Journal for Service Learning in Engineering, 2007, Vol. 2, No. 2, pp. 76-88.

[11]. W. K. Trotter, W. G. Heid, Jr. R. G.McElroy, "Review of Solar Energy for Agricultural products", U.S. Department of Agriculture Economics Statistics, and Cooperative Service, Aug. - 1979.

[12]. Mohammad Mehdi Salehi Dezfouli, ZafriAzran, MohdHafidz Ruslan, Ahmad Fudholi, KamaruzzamanSopian, "Experimental Investigate Of Draying Chili By Solar Assisted Heat Pump Dryer With Multifunctional Solar Thermal Collector", Solar Energy Research Institute University Kebangsaan, Malaysia.

[13]. TawonUsub, CharoenpornLertsatitthanakorn, NattapolPoomsa-ad, LamulWiset, Lifeng Yang, SirithonSiriamornpun, "Experimental performance of a solar tunnel dryer for drying silkworm pupae", Elsevier Ltd. 2008. pp. $209-216$. 